DOI: 10.12731/2218-7405-2018-1-167-174

УДК 37.026.8

\title{
ТЕРМИНОЛОГИЧЕСКАЯ \\ ГРАМОТНОСТЬ В ОБЛАСТИ ПСИХОЛОГИИ \\ ОБУЧАЮЩИХСЯ СОЦИАЛЬНО-ГУМАНИТАРНЫХ НАПРАВЛЕНИЙ ПОДГОТОВКИ
}

\section{Миронов А.Г.}

Статья посвящена исследованию уровня терминологической грамотности в области психологши обучающихся сочуиально-гуманитарных направлений подготовки как одного из важнейших педагогических условий усвоения содержания гуманитарных дисииплин и качества овладения профессиональными навыками.

Цель настоящей работы заключается в экспериментальной оченке уровня терминологической грамотности обучающихся в области психологии на этапах обучения бакалавриат и магистратура, юридических и профессионально-педагогического направлений подготовки.

Методической основой исследования послужили: педагогический эксперимент (констатирующий этап), опрос, общепринятые методы статистической обработки экспериментальных данных.

База исследований: Красноярский государственный аграрный университет, Юридический институт, Институт международного менеджмента и образования.

В результате исследовательской работы установлено, что в отношении 35-41\% психологических терминов и понятий обучающиеся испытывают значительные трудности в понимании или не знают вовсе. В современных образовательных условиях в ходе освоения учебных дисииплин следует актуализировать работу с понятийнотерминологическим аппаратом, иире и полнее используя глоссарные методы обучения, составление тезаурусов, работу с текстами с высокой частотой обращчения к специальным терминам. 
Ключевые слова: терминологическая грамотность; терминологический потенциал; обучающиеся вуза; сочиально-гуманитарные направления подготовки; условия усвоения дисцииплин.

\section{SOCIO-HUMANITARIAN STUDENTS TERMINOLOGICAL LITERACY IN PSYCHOLOGY}

\section{Mironov A.G.}

The article is devoted to the terminological literacy in psychology of students pursuing a bachelor's and a master's degree in socio-humanitarian training programmes.

The aim of the research work is the experimental assessment of terminological literacy level of students in different education degrees.

Methods: summative experiment, survey, methods of descriptive statistics.

Study base: Krasnoyarsk State Agrarian University, Law Institute, Institute of International Management and Education.

The result of the experimental work established the level of terminological literacy level in psychology between 56\% and 65\%, increasing progressively as course duration. Such a level while is not sufficient for future student's successful employment in socio-humanitarian professional sphere. Glossary methods and text instructions with high psychological terms frequency are recommended to be practiced in socio-humanitarian training courses.

Keywords: terminological literacy; terminological potential; students of the university; social and humanitarian areas of training; conditions for the assimilation of disciplines.

\section{Введение}

Терминологическая грамотность является важной и необходимой составляющей профессиональной и языковой компетентности по причине того, что специальная лексика и терминология отражают содержание будущей профессиональной деятельности, и является важным 
инструментарием. Особое значение данная компетентность имеет для обучающихся социально-гуманитарных направлений подготовки, для которых искусное оперирование психологическими терминами в устной и письменной речи, правильное понимание их значения и возможности применения является составляющей профессионального мастерства и эффективной профессиональной деятельности.

Терминологическая грамотность как составляющая трехуровневого понятия «терминологический потенциал» (терминологическая осведомленность $\rightarrow$ терминологическая грамотность $\rightarrow$ терминологическая компетентность [1]) является этапом развития личностных свойств слушателя за счет представления терминов и понятий предметной области и формирования на его основе предметно-практического и теоретического опыта личности. Будущим выпускниками социально-гуманитарных направлений подготовки, которые в своей профессиональной деятельности будут непосредственно общаться со специалистами психологического профиля, знание и понимание, какой термин обозначает то или иное понятие, как применять профессиональные термины в общении со специалистами, является необходимым компонентом их профессиональной компетентности.

Владение понятийно-терминологическим аппаратом в предметной области в научно-педагогической литературе рассматривается как одно из важнейших условий:

- качества усвоения содержания обучения, а в дальнейшем качества овладения профессиональными навыками [7].

- разрешения конфликта субъектного и общественно-исторического (научного) опыта обучающегося (который может вызывать как затруднения в обучении, так и отчуждение) с «созданием учебной доминаты» [5], базирующейся на содержательной составляющей субъектного опыта обучающихся [11].

- эффективного восприятия предметного содержания, как следствие развития мыслящей способности [9], повышения познавательного интереса и мотивации учения [8].

- реализации коммуникативно-деятельностного подхода в обучении [2]. 
Описание исследования. С целью экспериментальной оценки уровня терминологической грамотности обучающихся на базе ФГБОУ ВО «Красноярский государственный аграрный университет» были выделены экспериментальные группы обучающихся юридических направлений подготовки академического бакалавриата $(\mathrm{N}=70)$, магистратуры $(\mathrm{N}=45)$ и обучающихся академического бакалавриата по направлению подготовки «Профессиональное обучение (по отраслям)» $(\mathrm{N}=20)$. Выборка сплошная.

На первом этапе констатирующего эксперимента обучающиеся работали с перечнем наиболее употребляемых в психологии терминов (350 терминов), оценивая свой уровень владения каждым из них по трем категориям: 1) «свободно владею понятием, использую в речи, могу дать точное определение»; 2) «имею общее представление, ориентируюсь, затрудняюсь дать точное определение, в речи использую изредка или никогда»; 3) «термин незнаком» (номер соответствует обозначению в таблице результатов исследования).

На втором этапе эксперимента обучающимся на основе анализа профессиональных текстов, релизов, периодики, аналитических телепередач, и личного опыта коммуникативного взаимодействия со специалистами предлагалось сформировать список часто встречающихся психологических терминов, незнание значений которых существенно затрудняет коммуникацию и осмысление получаемой информации.

\section{Результаты и обсуждения}

Полученные данные, обработанные методами дескриптивной статистики, представлены в таблице.

Таблицุа.

Показатели уровня владения психологическими терминами

\begin{tabular}{|l|c|c|c|}
\hline \multirow{2}{*}{\multicolumn{1}{|c|}{ Экспериментальная группа }} & \multicolumn{3}{|c|}{ Уровень владения } \\
\cline { 2 - 4 } & \multicolumn{3}{|c|}{ термином, \% } \\
\hline Профессионально-педагогический бакалавриат (3-4 курс) & 65 & 25 & 10 \\
\hline Юридический бакалавриат (2 курс) & 56 & 25 & 19 \\
\hline Юридическая магистратура (1 курс) & 59 & 30 & 11 \\
\hline Юридический бакалавриат (заочное обучение) & 57 & 23 & 20 \\
\hline
\end{tabular}


Уровень терминологической грамотности обучающихся коррелирует с частотой обращения к психолого-педагогическим дисциплинам в учебных планах данных направлений подготовки, а также с годом обучения. В пределах экспериментальных групп во всех случаях отмечается относительно однородный уровень владения психологическими терминами $(V=8,5-11,9 \%)$, за исключением обучающихся по заочной форме, где коэффициент вариации $>20 \%$, что объясняется различиями в опыте и подготовке данного контингента. В целом, считаем, что полученные результаты свидетельствуют о недостаточном уровне терминологической грамотности в области психологии обучающихся по социально-гуманитарным направлениям подготовки.

Анализ и обобщение часто встречающихся психологических терминов, с которым обучающиеся испытывают затруднения позволил сформировать следующий перечень терминов: Амбивалентность, Астения, Аффект, Аффилиация, Бихевиоризм, Детерминизм, Инсайт, Интроспекция, Катарсис, Конформность, Локус контроля, Нонконформизм, Ригидность, Онтогенез, Плюрализм, Самоактуализация, Сублимация, Фрустрация, Эмпатия.

Важную особенность современных обучающихся, которую следует выделить - это клиповое сознание [3], которое проявляется в скорости мышления в условиях потока информации, скорости и объеме решения учебных задач, концентрации и распределении внимания с решения одной задачи на другую. В этой связи качество обработки новой «порции» знаний в условиях недостаточной терминологической грамотности снижается: происходит переключение внимания на решение новой, более понятной задачи.

Практические рекомендации. Анализ литературы, образовательных практик и результатов настоящего исследования послужили основой для разработки следующих рекомендации: в современных образовательных условиях в ходе освоения учебных дисциплин следует актуализировать работу с понятийно-терминологическим аппаратом, шире и полнее используя глоссарные методы обучения, составление тезаурусов, работу с текстами с высокой частотой об- 
ращения к специальным терминам. Хорошо зарекомендовали себя в повышении терминологической грамотности решение ситуационных задач, игровые методы [6], этимологические параллели [4] в ходе объяснения материала, что обусловлено иноязычным происхождением большого количества психологических терминов, понимание и осмысление которых облегчается в условиях высокого интереса обучающихся к иностранным языкам (в первую очередь к английскому).

\section{Выводы}

Проведенные исследования уровня терминологической грамотности в области психологии будущих специалистов в социально-гуманитарной сфере на этапе обучения в вузе демонстрируют недостаточный уровень владения обучающимися психологическими терминами и понятиями. В отношении $35-41 \%$ терминов обучающиеся испытывают трудности с понимаем или не знают вовсе. Результаты исследований и анализ современного образовательного процесса дают основание для рекомендации широкого и всестороннего применения глоссарного метода обучения и работу с текстами с высокой частотой обращения к специальным терминам.

\section{Список литературы}

1. Артюшкина Т.А. Лексикографические аспекты разработки учебного терминологического словаря бухгалтерского учета // Альманах современной науки и образования. Тамбов: Грамота, 2008. № 10 (17): в 2-х ч. Ч. I. С. 15-17.

2. Ассуирова Л.В. Образовательная технология риторизации // Гуманитарные науки и образование, 2010. №2. С. 15-18.

3. Гиренюк Ф.И. Клиповое сознание. Монография. М.: Изд-во Проспект, 2016. $256 \mathrm{c.}$

4. Медведева Н.П. Использование этимологических параллелей при изучении иностранных языков // Сборник научных трудов SWorld. 2011. T. 18. № 3. С. 60-62. 
5. Подходова Н.С. Субъектный опыт учащихся в преодолении их отчуждения от процесса обучения // Научное обозрение. Педагогические науки. 2015. № 3. C. 40. URL: https://science-pedagogy.ru/ru/ article/view?id=1171 (дата обращения: 01.04.2018).

6. Сарыев Р.Н. Терминологический потенциал обучающихся в сфере экономики и управления // Студенческая наука - взгляд в будущее: мат-лы XI Всерос. студ. науч. конф. Часть 3. Краснояр. гос. аграр. ун-т. Красноярск, 2016. С. 64-66.

7. Соловьева Т.В. Работа с понятиями и терминами как условие усвоения учебного предмета // Русский язык в национальной школе, 2015. № 3. C. 30-34.

8. Туова Т.Г., Мельникова Т.Н. Проблемы усвоения понятийно-терминологического аппарата географии в условиях билингвизма // Актуальные задачи педагогики: материалы VIII Междунар. науч. конф. (г. Москва, ноябрь 2017 г.). М.: Буки-Веди, 2017. C. 15-20. URL: https:// moluch.ru/conf/ped/archive/272/13104/ (дата обращения: 09.03.2018).

9. Ушинский К.Д. Избранные педагогические произведения. М.: Просвещение, 1968. 495 с.

10.Шабунина В.А., Дунаева Н.В., Шабунина А.К., Миронов А.Г. Современные подходы в терминологии профессионального образования. Москва-Красноярск, 2017. 562 с.

11. Якиманская И.С. Личностно-ориентированное обучение в современной школе. М.: Сентябрь, 2000.

\section{References}

1. Artjushkina T.A. Al'manah sovremennoj nauki i obrazovanija. Tambov: Gramota, 2008. № 10 (17). Part I, pp. 15-17.

2. Assuirova L.V. Gumanitarnye nauki i obrazovanie, 2010. №2, pp. 15-18.

3. Girenjuk F.I. Klipovoe soznanie [Clypeal consciousness]. M.: Izd-vo Prospekt, 2016. 256 p.

4. Medvedeva N.P. Sbornik nauchnyh trudov SWorld. 2011. V. 18. № 3, pp. 60-62.

5. Podhodova N.S. Nauchnoe obozrenie. Pedagogicheskie nauki. 2015. № 3. P. 40. https://science-pedagogy.ru/ru/article/view?id=1171 
6. Saryev R.N. Studencheskaja nauka-vzgljad v budushhee [Student science - a look into the future]. Part 3. Krasnojarsk, 2016, pp. 64-66.

7. Solov'eva T.V. Russkij jazyk v nacional'noj shkole, 2015. № 3, pp. 30-34.

8. Tuova T.G., Mel'nikova T.N. Aktual'nye zadachi pedagogiki [Actual problems of pedagogy]. M.: Buki-Vedi, 2017, pp. 15-20. https://moluch. ru/conf/ped/archive/272/13104/ (Accessed 09 March 2018).

9. Ushinskij K.D. Izbrannye pedagogicheskie proizvedenija [Selected pedagogical works]. M.: Prosveshhenie, 1968. 495 p.

10. Shabunina V.A., Dunaeva N.V., Shabunina A.K., Mironov A.G. Sovremennye podhody $v$ terminologii professional'nogo obrazovanija [Modern approaches in the terminology of vocational education]. Moscow-Krasnojarsk, 2017. 562 p.

11. Jakimanskaja I.S. Lichnostno-orientirovannoe obuchenie v sovremennoj shkole [Person-oriented learning in a modern school]. M.: Sentjabr', 2000.

\section{ДАННЫЕ ОБ АВТОРАХ}

Миронов Алексей Геннадьевич, доцент кафедры психологии, педагогики и экологии человека, председатель Совета молодых ученых аграрных образовательных и научных учреждений Сибирского и Дальневосточного федеральных округов, кандидат сельскохозяйственных наук, доцент

ФГБОУ ВО «Красноярский государственный аграрный университет»

просп. Мира, 90. г. Красноярск, Российская Федераџия, 660049 , Российская Федерация

lexamir13@mail.ru

\section{DATA ABOUT THE AUTHORS}

Mironov Aleksei Gennadievich, Associate Professor of the Department of Psychology, Education and Human Ecology, Candidate of Agricultural Science, Docent Krasnoyarsk State Agrarian University 90, Mira Ave., Krasnoyarsk, 660049, Russian Federation lexamir13@mail.ru

SPIN-code: 9873-0365 